reflected upon the student, and though he may bo unusually well armed at one part his armour has serious weaknesses. Such a scheme would relieve the strain of maintaining a staff for the primary and scientific work and allow the universities and university colleges to fulfil their proper duties to the profession. Dublin, Glasgow, and Edinburgh might be similar centres and work upon similar lines. This project I respectfully submit is feasible, cannot injure anyone, and only requires the support of the General Medical Council to effect the reform. Your space is too valuable to dilate upon other obvious advantages.--I am, Sirs, yours faithfully,

Feb. 18th, 1905.

R. C. H.

\section{EFFECTS OF ANESTHETICS UPON PLANTS.}

To the Editors of THE LANCET.

SiRs,--Besides the effect upon the sensibility of " mimosa pudica" noticed by your correspondent Dr. R. Macdonald and the enhancing of rest to which you refer several other effects of anæsthetics upon vegetable life have now been observed. It may interest Dr. Macclonald to be referred to some of these. The streaming of protoplasm, cell division, and cellular respiration are all affected in the direction of paralysis by solutions or vapours of ether and of chloroform. Elfving and Lauren ${ }^{1}$ state that respiration in the higher plants is increased by ether and by chloroform but this is denied by other authorities. Claude Bernard showed that fermentation can be inhibited by chloroform. Again photosynthesis (the manufacture of sugar and starch from $\mathrm{CO}_{2}$ and $\mathrm{H}_{2} \mathrm{O}$ in chlorophyll-containing cells) is stopped by placing plants in an atmosphere which contains quantities of ether not enough to stop respiration. It would seem indeed, generally speaking, that vegetable life is as susceptible as animal life to the peculiar action of anæsthetic drugs but these are not so easily brought to bear upon the regetable tissues as in the case of animals.

eb. 20tb, 1905. I am, Sirs, yours faithfully, J. BLUMFELD.

\section{THE TREATMENT OF FRACTURES BY EARLY STRAPPING, EARLY MASSAGE, AND EARLY MOVEMENT.}

To the Editors of THE LANCET.

SIRS,-Having for the last 20 years treated sprains, fractures, and dislocations upon the system described by Mr. J. Stafford Mellish in The LANCET of Feb. 11th, p. 350, and having applied such treatment to my own fractured leg some years ago, I am in a position to write with considerable personal knowledge of the results. My own case of Pott's fracture of the leg I brought before the Medical Society of London and it was reported in the British Medical Journal of Feb. 15th, 1896. It was also referred to in an article in The LanceT on Feb. 5th, 1898. A few of my personal experiences may be of interest now. My surgical friends were at first very much opposed to my using plaster strapping, but having applied it myself within half an hour of the accident it entirely prevented swelling of the injured part and gave me great comfort

Throughout the treatment I realised all the advantages which have been claimed for this system and I began to walk 21 days after the accident. It is always advisable to shave and to cleanse carefully the injured limb before applying the plaster. The plaster should be cut in strips from one to two inches wide, long enough to surround the limb and overlap at the ends. It should be just laid on the skin without any attempt to produce pressure. The ordinary adhesive strapping which does not require artificial heat is very effective, but all the rubber plasters are apt to irritate the skin. Oxide of zinc plasters suit some skins but the best kind is one called Eccles' plaster. Gentle massage cannot be commenced too early and Mr. Mellish's sugges. tion of applying the strapping from above down so as to facilitate this rubbing is much to be commended. The effect of massage in my own case was absolutely delightful.

While early movement is being carried out the bones may be steadied by the hands of the surgeon or by a temporary clamp located to the injured part. The whole treatment by strapping, early movement, and massage not only gives

Botanischer Jahresbericht, 1892, p. 92. immediate comfort to the patient but also prevents wasting of muscles and enables the patient to get about much earlier than under the old-fashioned plan of fixation for weeks. Moreover, it prevents the occurrence of that stiffness of joint which so often comes before the surgeon after fractures that have been treated by the ordinary plan.

I am, Sirs, yours faithfully,

E. NOBle Smith.

Queen Anne-street, London, W., Feb. 19th, 1905.

\section{DUODENAL ULCER.}

To the Editors of THE LANCET.

SiRs, - With reference to "flushing" in the treatment of perforated duodenal ulcers might I refer Mr. W. Bruce Clarke to the series of nine cases of perforated gastric ulcer, eight of whom recovered, published in THE LANCET of July 16 th, 1904, p. 145? Seven of these cases were under my care and two were under the care of Mr. T. Crisp English. Since then three cases of perforated duodenal ulcer, two of which recovered, have been treated by the same method of flushing at St. George's Hospital by Mr. English and myself. I feel very strongly from my experience of this flushing or irrigation method combined with suprapubic incision that it is a most efficient method of dealing with perforated ulcers, whether of the stomach or the duodenum.

I am, Sirs, yours faithfully,

Half Moon-street, Piccadilly, Feb. 19th, $1905 . \quad$ G. R. TURNER.

\section{To the Editors of THE LANCET.}

SIRS,-In reference to the questions of Mr. W. Bruce Clarke I desire to say:-

Firstly. The difficulty of diagnosis between the perforation of a duodenal ulcer and the perforation of the appendix is sometimes very great; so great, indeed, as to have misled surgeons of unquestioned aptitude in the recognition of these conditions. In my original paper in THE LANCET I showed that in approximately 40 per cent. of the cases of perforating duodenal ulcer that had been submitted to operation the incision had been made over the appendix. In my own experience no real difficulty has arisen, though one of the patients was sent into hospital with a diagnosis of acute appendicitis. The difficulty can only arise, it seems to me, after the lapse of a few hours; after the time, that is, during which the area of pain, rigidity, and tenderness has ceased to be local. After the first few hours the peritoneum along the outer side of the "hillock" and down the ascending colon becomes infected. It may be seen covered with plastic lymph when all other parts of the peritoneum are unharmed. In this stage a confusion of diagnosis is not improbable, for the localisation of the signs mentioned reproduces the circumstances of a case of appendicitis-the "mimicry," in fact, is complete. In the last stage of all, when the peritoneal infection is universal, the discovery of the point of origin of a general peritonitis is virtually impossible. Mr. Bruce Clarke's question may therefore be answered by the statement that in the early hours after a perforation diagnosis should be easy, after a few hours appendicitis may be mimicked, in the last stage of all an accurate diagnosis is extremely unlikely. Nowadays the cases are seen early and therefore, as Mr. Bruce Clarke says, the difficulty in diagnosis is not likely to arise when the cases are "earlier recognised and more promptly treated."

Secondly. The question of flushing and drainage of the peritoneum is determined entirely by the conditions found. In the first few hours it is not necessary (it is probably harmful) to do either; in the stage of general infection it is my practice to drain freely and, generally, to flush the peritoneum with hot saline solution. The last case in my list (Series 1) was an exemplary instance of the kind of case that would seem to demand irrigation and drainage. The facts that Mr. Bruce Clarke has not, except in the one case mentioned, felt any difficulty in making a correct diagnosis and that he regards the flushing of the peritoneum as unnecessary are both eloquent in proof of the earlier recognition of the cases in his own experience. There are, however, cases, unfortunately still too many, in which the recognition of the disease is tardy ; in them difficulties of diagnosis are not unlikely to be encountered and measures necessary for the cleansing of the grcatly damaged peritoneum must still be practised. I am, Sirs, yours faithfully. Leeds, Feb. 20tb, 1905.

B. G. A. MOYNIHAN. 